\title{
The Yield of Birth Cohort Screening for Hepatitis C in Community Health Centers
}

\author{
Sarah E. Rowan, MD ${ }^{1,2}$, Larissa Muething, MD², Kirsten Spielmann, MS LCSW , \\ Joshua Blum, $M D^{1,2}$, Yingbo Lou, $\mathrm{MS}^{7}$, Shawni Vaughn, $B A^{7}$, and William J. Burman, \\ $M D^{1,2}$
}

'Denver Health and Hospital Authority, Denver, CO, USA; ${ }^{2}$ University of Colorado Denver, Aurora, CO, USA.

J Gen Intern Med 34(10):2003-4

DOI: $10.1007 / \mathrm{s} 11606-019-05105-4$

(c) Society of General Internal Medicine 2019

\section{INTRODUCTION}

In 2012, the Centers for Disease Control and Prevention released recommendations to screen all individuals born 1945-1965 for hepatitis C (HCV), regardless of risk factors. ${ }^{1}$ In response to this recommendation and in anticipation of a new generation of effective and welltolerated HCV medications, we implemented a screening program in two urban community health centers (CHCs). The objective was to identify individuals living with previously undiagnosed $\mathrm{HCV}$ and to facilitate linkage-to-care.

\section{METHODS}

This study took place at two CHCs in Denver, CO. Participants were born between 1945 and 1965, were attending routine primary care appointments, and had never been fully screened for HCV. We included individuals who had prior positive $\mathrm{HCV}$ antibody tests but no follow-up RNA testing. Navigators approached individuals while they were waiting for their providers and offered to order HCV testing. The navigator followed up all tests and provided counseling and linkage support. We documented patient characteristics, test results, and progression through the $\mathrm{HCV}$ care continuum through 2018. Factors associated with a positive RNA result were evaluated with bivariate analyses.

This study was evaluated by the Colorado Multiple Institutional Review Board and deemed to be a quality improvement project thus exempt from review.

Data Availability. De-identified data sets are available upon request to corresponding author.

Prior Presentations: The preliminary results of this study were presented at ID Week 2014 in Philadelphia, PA, as an oral abstract presentation. The results have not been previously published.

Published online June 13, 2019
RESULTS

During the calendar years of 2013-2014, 3940 individuals were eligible for birth cohort-based HCV screening, and 3218 (82\%) consented to testing. Of those who did not test, most had sameday appointments and were not offered testing because the navigator was not aware of the visit. Of the individuals not previously screened, 329 had positive HCV antibodies (10.5\%). Of those, 211 tested positive for HCV RNA (7\%) (see Table 1). Of the individuals with past positive antibody tests but no follow-up RNA testing, an additional 78 individuals tested positive for HCV RNA, for a total of 289 individuals in the full cohort with detectable HCV RNA, $32 \%$ of whom endorsed a history of ever injecting drugs. Factors associated with a positive HCV RNA test included being Black, non-Hispanic, male, US-born, and having public insurance.

Table 1 Individuals in the 1945-1965 Birth Cohort Tested for HCV at Two Community Health Centers, 2013-2014

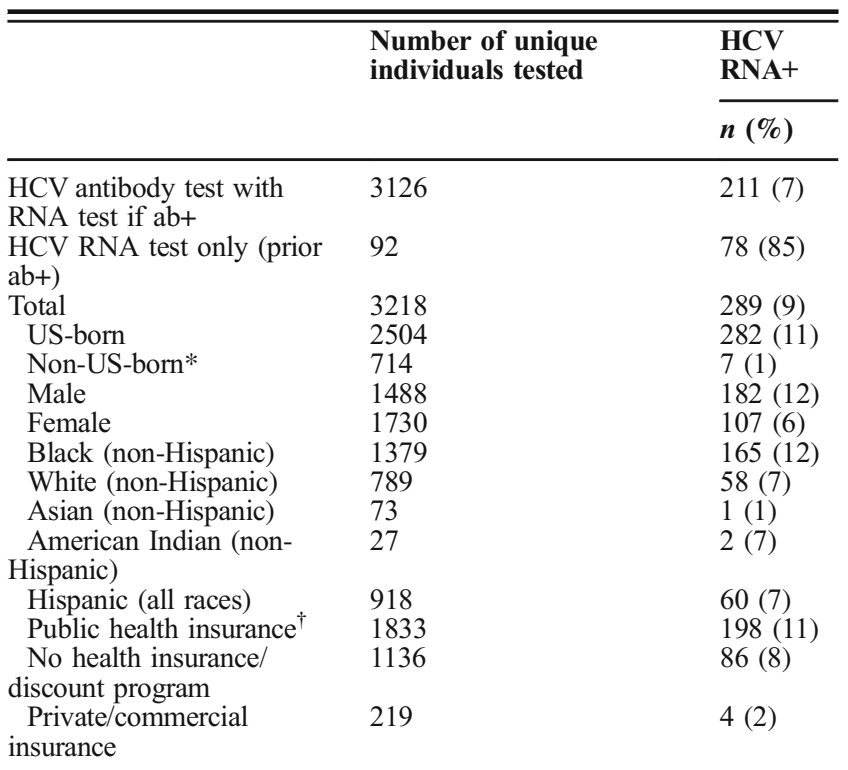

*The majority of the non-US-born individuals were born in Mexico $(460,65 \%)$

${ }^{\dagger}$ Includes Medicaid and Medicare 


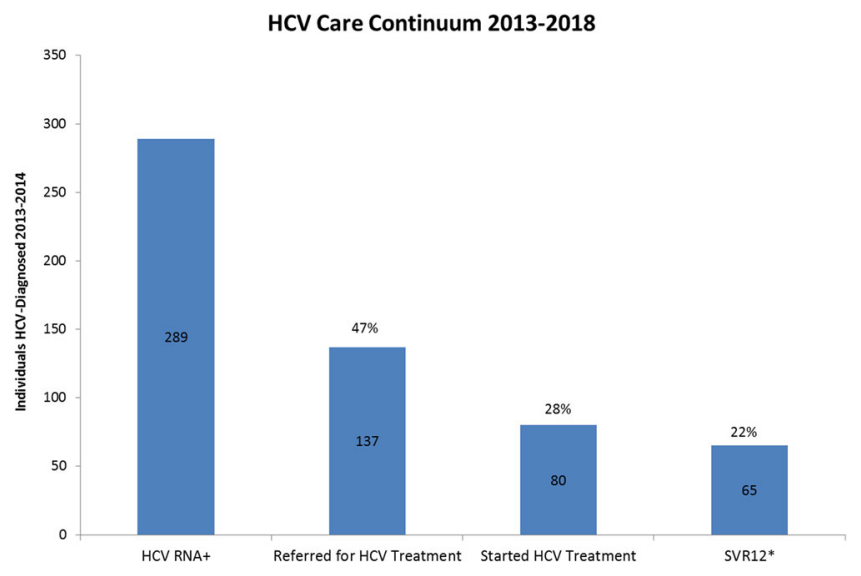

Fig. 1 HCV Care Continuum 2013-2018. Continuum of care for individuals newly HCV-diagnosed (RNA+) 2013-2014 with followup through 2018. *Of the 15 individuals without evidence of SVR12, 13 individuals completed treatment $<12$ weeks prior to the end of the follow-up period, thus could not be assessed for SVR12 yet, and 2 individuals has undetected HCV RNA levels on treatment but were then lost to follow-up. HCV, hepatitis C virus; SVR12, sustained virologic response 12 weeks after the end of therapy.

Of those who tested positive for HCV RNA, 137 individuals $(47 \%)$ were referred for HCV treatment, $80(28 \%)$ started treatment, and $65(22 \%)$ had evidence of sustained virologic response 12 weeks after treatment completion (SVR12) (see Fig. 1). The most commonly documented reasons for nonreferral were substance abuse and poorly controlled comorbidities. Of the 15 treated individuals without evidence of SVR12, 13 were not yet 12 weeks post-treatment, and 2 individuals had undetected viral loads during treatment but did not return for SVR12 testing.

\section{DISCUSSION}

Among previously unscreened "baby boomers," $7 \%$ of the cohort had evidence of active HCV. The proportion increased to $9 \%$ when we included individuals with a history of positive $\mathrm{HCV}$ antibody results but no prior RNA testing. Similarly, high prevalence of $\mathrm{HCV}$ has been reported in other CHCs across the country. ${ }^{2,3}$ Limitations of this study are that we did not capture the reasons why individuals declined testing or the prevalence of previously diagnosed $\mathrm{HCV}$, which would have enabled estimation of total HCV prevalence among the birth cohort. In all subgroups evaluated, the frequency of positive HCV RNA results was $\geq 1 \%$, ranging up to $12 \%$ among Blacks and men. Like other studies, the majority of individuals who tested positive for HCV RNA in our study did not endorse a history of injection drug use. ${ }^{4}$ These findings support recommendations for universal birth cohort-based testing, particularly in urban CHCs. ${ }^{1,5}$ As HCV treatment becomes increasingly accessible throughout the country, highyield screening efforts like this program will be crucial to curbing the high rates of morbidity and mortality caused by HCV in the USA. ${ }^{6}$

Corresponding Author: Sarah E. Rowan, MD; Denver Health and Hospital Authority, 601 Broadway, Denver, CO 80203, USA (e-mail: sarah.rowan@dhha.org).

Contributors The clinical staff at the two participating CHCs, the patients, and the HCV navigators all contributed to this work.

Funding This work was funded by CDC PPHF 1U51PS003805-O through the CDC's Hep TLC initiative.

\section{Compliance with Ethical Standards:}

Conflict of Interest: Dr. Rowan receives salary support through research grants from Gilead Sciences, Inc. All remaining authors declare they do not have a conflict of interest.

Publisher's Note: Springer Nature remains neutral with regard to jurisdictional claims in published maps and institutional affiliations.

\section{REFERENCES}

1. Smith BD, Morgan RL, Beckett GA, et al. Recommendations for the identification of chronic hepatitis $\mathrm{C}$ virus infection among persons born during 1945-1965. MMWR Recommendations and reports: Morbidity and mortality weekly report Recommendations and reports/Centers for Disease Control. 2012;61(RR-4):1-32.

2. Patel RC, Vellozzi C, Smith BD. Results of Hepatitis C Birth-Cohort Testing and Linkage to Care in Selected U.S. Sites, 2012-2014. Public Health Rep. 2016;131 Suppl 2:12-19.

3. Coyle $\mathbf{C}$, Viner $\mathbf{K}$, Hughes $\mathbf{E}$, et al. Identification and Linkage to Care of HCV-Infected Persons in Five Health Centers - Philadelphia, Pennsylvania, 2012-2014. MMWR Morbidity and mortality weekly report. 2015;64(17):459-463.

4. Cornett JK, Bodiwala V, Razuk V, Shukla D, Narayanan N. Results of a Hepatitis C Virus Screening Program of the 1945-1965 Birth Cohort in a Large Emergency Department in New Jersey. Open forum infectious diseases. 2018;5(4):ofy065.

5. Moyer VA, Force USPST. Screening for hepatitis $\mathrm{C}$ virus infection in adults: U.S. Preventive Services Task Force recommendation statement. Annals of internal medicine. 2013;159(5):349-357.

6. Ly KN, Hughes EM, Jiles RB, Holmberg SD. Rising Mortality Associated With Hepatitis C Virus in the United States, 2003-2013. Clinical infectious diseases : an official publication of the Infectious Diseases Society of America. 2016;62(10):1287-1288.

Publisher's Note Springer Nature remains neutral with regard to jurisdictional claims in published maps and institutional affiliations. 